and Principals, the House of Lords Select Committee on Science and Technology, the BMA, the Association of University Teachers, and the Royal College of Nursing, among others, to have significant implications and to raise fundamental questions as to the very nature of independent research. In view of the seriousness of the issue for the future of all research supported by the $\mathrm{DoH}$ or DSS every effort was made by the research community to obtain clarification about how the new contract would be interpreted in practice.

As reported in the $B M \mathcal{F} \mathrm{Mr}$ Jack Barnes, director of research management at the $\mathrm{DoH}$, reaffirmed ministerial statements that neither the DoH nor the DSS intends to interfere with publication on the grounds of factual content.' It would seem that the only reasons for refusal of consent to publish envisaged by officials relate to the publication of material likely to lead to legal action against the crown.

The association warmly welcomes these assurances and is hopeful that no problems concerning the freedom to publish arise. It is vital, however, that the situation is carefully monitored by the research community and for this purpose we ask that any examples of attempted censorship - or of comments from officials which might lead to forms of self censorship-be brought to the attention of the secretary of the association.

LUKE ZANDER

Department of General Practice,

United Medical and Dental Schools of (juy's and

St Thomas's Hospitals,

London SE1 7EH

NICHOLAS MAYS

Department of Community Medicine,

United Medical and Dental Schools of Guy's and

St Thomas's Hospitals,

London SE1 $7 \mathrm{EH}$

1 Groves T. Government funded researchers accept new contract. BrMed f 1989:299:586. (2 September.)

\section{Food safety awareness}

SIR, - Dr J M Cowden and colleagues conclude that there is a need for public health education to help reduce food poisoning caused by Salmonella enteritidis phage type $4 .^{\prime}$ Given the continuing media awareness and criticisms of the Department of Health for giving conflicting or delayed advice, it seemed interesting to survey the recipes in women's magazines. As $15 \%$ of the patients reported on by Dr Cowden and colleagues were children aged under 10 years the magazines chosen were those directed at housewives and mothers.

Twenty three magazines in the women's section and homes section on the shelves in a well stocked newsagent were studied, all of which had a cookery section. Four magazines contained at least one recipe using raw eggs that would not be cooked before being eaten. These were Family Circle (October 1989; three recipes), Essentials (October 1989; two recipes), Bella (30 September 1989; one recipe), and Best (September 1989; one recipe). The number of raw eggs (yolk or white, or both) for each recipe was $3,3,4,2,6,2$, and 9 .

The comments on the recipes in Family Circle show particular lack of awareness of the food hygiene message: one was for ice cream (a favourite of children) and one had been prepared specifically for "my tot." These recipes had been published in 1986 and in November 1988 and were reprinted without riders in the light of new recommendations. Another that used nine eggs discussed the "recent controversy over egg production in the UK" but said that the reader "should have no worries if you buy from a respectable source-like a local large supermarket." At present there is in fact no way of being absolutely certain that eggs from any source are entirely free of salmonella.

There is still much to be done to bring awareness of the problems of food safety to the public.
Perhaps cookery writers and editors should be urged to double check before printing recipes such as these.

ALYSON ELLIMAN DAVID ELLIMAN

Carshalton Beeches,

Surrey SM5 4PD

1 Cowden JM, Lynch D, Joseph CA, et al. Case-control study of infections with Salmonella enteritidis phage type 4 in England. BrMed 7 1989;299:771-5. (23 September.)

\section{Health for all by the year 2000}

SIR,-Sometimes I think that mine is a small, lone voice crying in the wilderness. Therefore it is refreshing, although not encouraging, to find that I am not alone, ${ }^{12}$ and that others also see the grossly inadequate health care services in the Third World and the overwhelming social problems preventing their uptake.

Enthusiastic international organisations and conferences are led by those at the top of their specialties, speaking to the convinced, converted elite. Though there are exceptions, these elite rarely work with the poorest of the poor. Our hospital is unable to recruit national doctors as it is in the forgotten north of the country where the climate is severe, the people are poorest, and private practice is not feasible. Instead they choose to supplement their incomes in the south while awaiting scholarships that will take them overseas Not many return. Whose responsibility is it to look after the rural poor?

Where health care facilities do exist the quality of care may leave much to be desired. Corruption is rife, motivation and standards are low, and technology is inappropriate. The few good or even outstanding staff are frustrated and discouraged by poor administration, unreliable supplies, and unrecognised service. These problems are not unique to government hospitals either-agency and mission hospitals also have their share.

Ignorance among the populace allows treatment by traditional methods to continue until the patient is extremely ill and arrives on the hospital doorstep. That is if they arrive at all; transportation is a major problem. A grand multipara who has been in labour for two days before being transported overnight in a donkey cart does not arrive in a very good condition. Among patients reaching us the maternal mortality is $17 / 1000$ and the perinatal mortality $110 / 1000$. Who can guess at the true mortality for women delivering unsupervised in the villages? Whether or not the woman survives the relatives still have to pay for treatment, and if the hospital is attempting to recover costs the fees may be above their means. Surely richer parts of the country have a responsibility towards poorer communities?

Health education seems to be slow to make headway in these rural societies. Family planning makes little sense when "children are God's will" or "my husband wouldn't agree." Perhaps the family planning comes later, as yet another child dies of malnutrition, but at what price to the mother's health? Then comes the problem of AIDS. In the past six months we have had several confined cases on the wards. One young man was soon going to be discharged, so I spent time counselling him. I explained the sexually transmissive nature of the disease and advised that he abstain from sexual intercourse or at least use condoms. A week later the hospital was informed that the same young man stood nightly at a street corner in the centre of town buying unsafe sex from as many girls as possible. His rationale? He didn't want to die alone; an attitude that the nurses assure me is not uncommon. A medical journal reported that Ghana has established facilities for screening blood for HIV. During the rains this year we gave transfusions to more than 20 children daily for life threatening anaemia secondary to malaria. The "facilities" have yet to reach us.

I probably sound sceptical; but so are many of the expatriate doctors I meet out here. The scepticism is born out of a deep concern for the patients we meet daily and the ones who never reach us. Of course we need the international organisations and overseas consultants who maintain their vision and enthusiasm. They have a much wider overall view than those of us working in the "bush." But for us the problems sometimes seem overwhelming, and development, if happening at all, is painfully slow.

There are many problems that I do not understand, of which inappropriate training of inappropriate staff is but one. When I leave in December there will be one Dutch doctor left for 250 beds. Surely it's time to train more nurses to run the hospital as medical assistants. Likewise much of the emergency surgery such as performing caesarean sections, correcting incarcerated hernias, etc, could be done by appropriately trained theatre staff. Unfortunately the government does not allow nurses to operate. So what will happen to the grand multipara on the donkey cart when the Dutch doctor is ill? I agree with Dr DeWindHealth for all by the year 2000: we might not get there.

Bawku Hospital,

ALISON FIANDER

PO Box 45,

Bawku, Ghana

1 DeWind CM. Health for all by the year 2000: why we might not get there. Br Med f 1989;299:867. (30 September )

Potter AR. May God have mercy on us all. Br Med f 1989;299: 629. (2 September.)

\section{Drug Points}

\section{Lofepramine and motor neuropathy}

Dr J A HewitT (Psychogeriatric Department, Barncoose Hospital, Redruth TR15 3TR) and $\mathrm{Mr}$ JoHN GLINN (Pharmacy Department, Royal Cornwall Hospital, Truro TR1 3LJ) write: An 84 year old woman was admitted with an 18 month history of lethargy and intermittent agitation. Despite a good appetite she had lost $6 \mathrm{~kg}$ during this period. Her medical history was unremarkable but she had a strong family history of depressive illness. The only medication she had taken during this time was a few tablets of thioridazine $10 \mathrm{mg}$. On examination she had a cachectic appearance, pronounced psychomotor retardation, nihilistic delusions, and delusions of poverty. Physical examination showed no other abnormalities. Investigations including full blood count, erythrocyte sedimentation rate, urea and electrolyte concentrations, and liver and thyroid function tests gave normal results, as did chest radiography and electrocardiography.

Depressive illness was diagnosed and the patient started on lofepramine $70 \mathrm{mg}$ twice daily. After nine days without response the dose was increased to $70 \mathrm{mg}$ three times a day. After one month's treatment she had developed a high stepping gait. Examination showed an inability to dorsiflex her feet. Reflexes were present, and sensory functions, except for vibration sense, were normal. Investigations were repeated but no abnormalities found. Lofepramine was suspected of being the cause and was stopped. While her mental state did not change, eight weeks after stopping treatment her footdrop improved such that her gait was no longer high stepping.

An on line search failed to identify any reported cases of motor neuropathy with lofepramine. Other tricyclic antidepressants, however, notably amitriptyline and imipramine (the latter being metabolised through desipramine in the same way 
as lofepramine), have caused neuropathies of a predominantly motor type..$^{2}$ Casarino has described a case of reversible motor neuropathy, manifested as bilateral footdrop, after three weeks of amitriptyline therapy. ${ }^{3}$ The manufacturers of lofepramine (E Merck) are not aware of any cases of motor neuropathy with the drug. This case has been reported to the Committee on Safety of Medicines, which knows of only a few reports of lofepramine causing adverse effects on the peripheral nervous system. Although it is difficult to attribute this woman's motor neuropathy directly to lofepramine, we draw attention to a previously unreported potential side effect of this drug.

1 Blain PG, Stewart-Wynne E. Neurological disorders. In: Davies DM, ed. Textbook of adverse drug reactions. Oxford: OUP, 1985:501-2.

2 Lane RJM, Routledge PA. Drug induced neurological disorders. Drugs 1983;26:137-9.

3 Casarino JP. Neuropathy associated with amitriptyline: bilateral footdrop. NY State $\mathcal{F}$ Med 1977;77:2124-6.

\section{Cyclosporin decreases nifedipine metabolism}

Drs J P McFadden, J E Pontin, A V Powles, L FRY, and J R IDLE (Departments of Pharmacology and Dermatology, St Mary's Hospital and Medical School, London W2) write: In common with several other drugs nifedipine is metabolised by a glucocorticoid inducible cytochrome P450 enzyme, P450pcn. This same P450 isozyme has recently been shown to be the major cyclosporin metabolising enzyme in human liver.' In our psoriasis clinic we have observed reactions to nifedipine among patients taking cyclosprin. A 44 year old woman, who developed hypertension while taking cyclosporin for psoriasis $(4 \mathrm{mg} / \mathrm{kg} /$ day), was started on nifedipine $40 \mathrm{mg} / \mathrm{day}$. At follow up two weeks later she complained of unpleasant "burning" sensations two hours after taking the nifedipine. The nifedipine was stopped, with abatement of the symptoms, but on restarting treatment she complained of severe flushing reactions, which again stopped after the drug was withdrawn. Another patient, a 54 year old woman taking cyclosporin $(2 \mathrm{mg} / \mathrm{kg} /$ day $)$ for psoriasis, developed a rash while taking nifedipine $20 \mathrm{mg}$ twice daily, which cleared after stopping the drug. Data from the Committee on Safety of Medicines reveal that symptoms of paraesthesia, flushing, and rash are all common adverse effects of nifedipine. To assess the possible interaction of cyclosporin and nifedipine at a metabolic level we performed a study to assess the effect of cyclosporin on P450pen enzyme activity.

Eight psoriatic patients (three men, five women; mean age 49 (range 32-64) years) were tested for P450pcn enzyme activity while taking cyclosporin $(3 \mathrm{mg} / \mathrm{kg}$ in seven subjects, $4 \mathrm{mg} / \mathrm{kg}$ in one) and one week after cessation of the drug. All were given an oral $5 \mathrm{mg}$ dose of nifedipine (Adalat, Bayer) after an overnight fast and voiding of the bladder. All urine collected in the eight hours after the dose was bulked and an aliquot stored at $-20^{\circ} \mathrm{C}$. Analysis of the urine for the principal metabolite of nifedipine MII was by automated capillary gas chromatography. ${ }^{2} \mathrm{P} 450 \mathrm{pcn}$ activity was assessed by measuring the excretion of MII, expressed as percentage recovery (MII excreted over eight hours divided by the dose given and multiplied by 100 ).

The mean percentage recovery while patients were not taking cyclosporin was $51 \cdot 75$ (SD 13.59)\% compared with a mean of $34.58(10 \cdot 14) \%$ while taking cyclosporin $(p<0 \cdot 05)$. Thus cyclosporin in vivo decreased $P 450 \mathrm{pcn}$ availability, the metabolism of nifedipine presumably being reduced through direct competition with cyclosporin.

Nifedipine is an effective, relatively safe antihypertensive agent; it has been claimed to be nephroprotective in subjects treated with cyclo- sporin, ${ }^{3}$ although further studies are required to substantiate this. ${ }^{+}$Our study, however, implies that it may be unwise for nifedipine to be prescribed in conjunction with cyclosporin without careful monitoring for side effects. The basis of their interaction would be competition for metabolism by cytochrome P450pcn.

1 Kronbach T, Fischer V, Meyer UA. Cyclosporin metabolism in human liver. Clin Pharmacol Ther 1988;43:630-5.

2 Schmid BJ, Perry HE, Idle JR. Determination of nifedipine and its three principal metabolites in plasma and urine by automated electron-capture capillary gas-liquid chromatography. I Chromatogr 1988;425: 107-19.

3 Feehally J, Walls J, Mistry N, et al. Does nifedipine ameliorate cyclosporin A nephrotoxicity? Br Med f 1987;295:310.

$4 \mathrm{Kwan} J \mathrm{~T}$, Foxall PJ, Townend JN, Bending MR, Eisenger AJ. Does nifedipine ameliorate cyclosporin nephrotoxicity? BrMed f 1987;295:851.

\section{Peripheral neuropathy and mesalazine}

Dr D K Woodward (Department of Medicine, Bradford Royal Infirmary, Bradford BD9 6RJ) writes: Peripheral neuropathy is a well documented effect of treatment with sulphasalazine ${ }^{2}$ (Pharmacia Ltd, personal communication) but rarely appears to have been reported in association with mesalazine (enteric coated 5-aminosalicylic acid) (Smith, Kline and French Laboratories, personal communication). I describe a patient with ulcerative colitis who developed neuropathy after starting treatment with mesalazine, which resolved when the drug was discontinued.

A 38 year old woman developed symptoms of ulcerative colitis in November 1986 and was prescribed mesalazine $400 \mathrm{mg}$ three times a day by her general practitioner. She was admitted for rectal biopsy in December 1986, which confirmed non-specific colitis. At this time she complained of numbness of her feet at night. She was changed to sulphasalazine $1 \mathrm{~g}$ three times a day but could not tolerate it because of gastrointestinal side effects and so started taking mesalazine again, $400 \mathrm{mg}$ three times a day, in January 1987. In April 1988 she was referred to the medical outpatient department, complaining of poor concentration, forgetfulness, numb feet, and tiredness in her leg muscles. Nerve conduction studies confirmed a mixed sensorimotor neuropathy, predominantly affecting the legs. Further investigation (including biochemical profile, glucose tolerance test, vitamin $B_{12}$ and folate concentrations, serum and urine protein electrophoresis, and urine porphyria screen) showed no apparent underlying cause for her symptoms. Mesalazine was suspected and discontinued in September 1988. By November 1988 her symptoms had largely resolved, correlating with improvement in repeat nerve conduction studies.

Sulphasalazine is metabolised by colonic bacteria into sulphapyridine and 5 -aminosalicyclic acid moieties. About $20 \%$ of patients taking sulphasalazine develop adverse reactions, ${ }^{3+}$ principally fever, rashes, vomiting, and reversible blood dyscrasias, usually related to the sulphonamide component.' Hepatitis, encephalitis, and neuropathy have also been reported. ${ }^{16}$; The mechanism of the neurological complications is obscure; the 5-aminosalicylic acid moiety is thought to be an unlikely cause because of the very low plasma and central nervous system concentrations achieved after oral or rectal administration. ${ }^{18}$

Despite the poor absorption of mesalazine, however, systemic side effects such as deteriorating renal function have been observed. ${ }^{9}$ In this patient neuropathy was associated with mesalazine; at the time of writing the Committee on Safety of Medicines had received three reports of neuropathy and one each of sensory disturbance, hyperaesthesia, paraesthesia, and neuralgia (personal communication)..$^{10}$ These observations suggest that sulphasalazine associated neuropathy cannot be assumed to be sulphonamide toxicity, as is usually thought. Caution is necessary when considering replacing sulphasalazine with mesalazine in a patient who has developed neuropathy.

I thank Dr Shaw for allowing me to report on this patient.

1 Wallace IW. Neurotoxicity associated with a reaction to sulphasalazine. Practitioner 1970;204:850-1.

2 Price TR. Sensorimotor neuropathy with sulphasalazine. Postgrad Med F 1985;61:147-8.

3 Collins JB. Adverse reactions to salicylazosulfapyrine in treatment of ulcerative colitis. South Med f 1968;61:354

4 Das KM, Eastwood MA, McManus JP, et al. Adverse reactions during salicylazosulfapyridine therapy and the relation with drug metabolism and acetylator phenotype. $N$ Engl f $\mathrm{Med}$ 1973;289:491-5

5 Klotz U. Clinical efficacy of oral 5-aminosalicylic acid in the treatment of inflammatory bowel disease. Am $\mathcal{F}$ Gastroentero 1985;88:660.

6 Smith MD, Gibson GE, Rowland R. Combined hepatotoxicity and neurotoxicity following sulphasalazine administration Aust NZ $\mathcal{J}$ Med 1982;12:76-80.

7 Mihas AA, Goldberg DJ, Slaughter RL. Sulfasalazine toxic reaction: hepatitis, fever, and skin rash with hypocomplementaemia and immune complexes. $\mathscr{F} A M A$ 1978;239:2590-1.

8 Klotz U, Maier KE. Pharmacology and pharmacokinetics of 5-aminosalicylic acid. Dig Dis Sci 1987;32:465-505.

9 Riley SA, Mani V, Goodman MJ, et al. Comparison of delayed release 5-aminosalicylic acid (mesalazine) and sulphasalazine in the treatment of mild to moderate ulcerative colitis relapse. Gut 1988;29:669-74.

10 Hebal FM, Greenberg GR. Treatment of ulcerative colitis with oral 5-aminosalicylic acid including patients with adverse reactions to sulphasalazine. Am f Gastroenterol 1988;83:15-9.

Identification of toga-like virus in fulminant hepatitis attributed to minocycline therapy

Drs Elizabeth FagaN and Roger Williams (Liver Unit, King's College School of Medicine, London SE5 9PJ) write: Drs M G Davies and P J W Kersey described fulminant hepatitis and exfoliative dermatitis associated with minocycline therapy. ${ }^{\prime}$ We would like to add the virological findings in case 2 , which were not reported by the authors and have now been published.

Liver transplantation was carried out on 16 May 1988 , which was three days after this patient's admission to the liver failure unit, King's College Hospital, because of deteriorating liver function and progressive hepatic encephalopathy (grade III-IV coma). Regrafting was carried out 48 hours later because of mechanical obstruction of venous return. The serum aspartate aminotransferase value rapidly rose to $5810 \mathrm{IU} / 1$ (prothrombin time $21 \mathrm{~s}$ prolonged) on $23 \mathrm{May}$. She was transplanted for the third time ( 26 May) but died 24 hours later from gastrointestinal haemorrhage.

Electron microscopic studies of the origina liver and the two successive grafts showed viruslike particles $(60-70 \mathrm{~nm})$ with spiked surfaces budding into cell vacuoles. Rod shaped inclusions were seen in the nuclei of the hepatocytes. Ultrastructural features resembled those of the RNA containing arboviruses, the Togaviridae.

We cannot exclude minocycline as the cause of the rash and the hepatic dysfunction, but the clinical course and similar virus-like particles have been found in two other patients with fulminant hepatitis who never received minocycline. ${ }^{123}$ Also an RNA containing virus of similar size and resembling the Togaviridae has recently been isolated in parenteral chronic non-A, non-B hepatitis. ${ }^{+}$

These findings have been reported to the Committee on Safety of Medicines.

1 Davies MG, Kersey PJW. Acute hepatitis and exfoliative derma itis associated with minocycline. $\mathrm{Br}$ Med 7 1989;298:1523-4. (3 June.)

2 Fagan EA, Ellis DS, Tovey GM, et al. Toga-like virus as a cause of fulminant hepatitis attributed to sporadic non-A, non-B. f Med Virol 1989;28:150-5.

3 Fagan EA, Ellis DS, Portmann B, Tovey GM, Williams R, Zuckerman AJ. Microbial structures in a patient with sporadic non-A, non-B fulminant hepatitis treated by liver transplant:tion. J Med Virol 1987;22:189-98.

4 Choo Q-L, Kuo G, Weiner AJ, Overby LR, Bradley DW, Houghton $M$. Isolation of a CDNA clone derived from a blood borne non-A, non-B viral hepatitis genome. Science 1989;244 $359-62$ 